\title{
Apoptotic cell death induced by dendritic derivatives of aminolevulinic acid in endothelial and foam cells co-cultures
}

\author{
Mariela A. Céspedes ${ }^{1}$ - Daniel A. Saénz ${ }^{1} \cdot$ Gustavo H. Calvo ${ }^{1} \cdot$ Marina González $^{2}$ - Alexander J. MacRobert ${ }^{3}$. \\ Sinan Battah ${ }^{4}$. Adriana G. Casas ${ }^{1}$. Gabriela M. Di Venosa ${ }^{1}$
}

Received: 11 December 2020 / Accepted: 12 February 2021 / Published online: 6 April 2021

(c) The Author(s), under exclusive licence to European Photochemistry Association,European Society for Photobiology 2021

\begin{abstract}
Photodynamic therapy (PDT) is an effective procedure for the treatment of lesions diseases based on the selectivity of a photosensitising compound with the ability to accumulate in the target cell. Atherosclerotic plaque is a suitable target for PDT because of the preferential accumulation of photosensitisers in atherosclerotic plaques. Dendrimers are hyperbranched polymers conjugated to drugs. The dendrimers of ALA hold ester bonds that inside the cells are cleaved and release ALA, yielding PpIX production. The dendrimer 6m-ALA was chosen to perform this study since in previous studies it induced the highest porphyrin macrophage: endothelial cell ratio (Rodriguez et al. in Photochem Photobiol Sci 14:1617-1627, 2015). We transformed Raw 264.7 macrophages to foam cells by exposure to oxidised LDLs, and we employed a co-culture model of HMEC-1 endothelial cells and foam cells to study the affinity of ALA dendrimers for the foam cells. In this work it was proposed an in vitro model of atheromatous plaque, the aim was to study the selectivity of an ALA dendrimer for the foam cells as compared to the endothelial cells in a co-culture system and the type of cell death triggered by the photodynamic treatment. The ALA dendrimer 6m-ALA showed selectivity PDT response for foam cells against endothelial cells. A light dose of $1 \mathrm{~J} / \mathrm{cm}^{2}$ eliminate foam cells, whereas less than $50 \%$ of HMEC-1 is killed, and apoptosis cell death is involved in this process, and no necrosis is present. We propose the use of ALA dendrimers as pro-photosensitisers to be employed in photoangioplasty to aid in the treatment of obstructive cardiovascular diseases, and these molecules can also be employed as a theranostic agent.
\end{abstract}

Keywords Photodynamic therapy $\cdot$ Aminolevulinic acid $\cdot$ Dendrimers $\cdot$ Atheromas $\cdot$ Tumour $\cdot$ Macrophages

Adriana G. Casas

adriana@fcen.uba.ar

$\triangle$ Gabriela M. Di Venosa

gabrieladivenosa@yahoo.com.ar

1 Centro de Investigaciones Sobre Porfirinas y Porfirias (CIPYP), Hospital de Clínicas José de San Martin, Universidad de Buenos Aires and CONICET, Avenida Córdoba 2351, 1er subsuelo, 1120 AAF Autonomous City of Buenos Aires, Argentina

2 Facultad de Ciencias Médicas, Centro Científico Tecnológico La Plata, Instituto de Investigaciones Bioquímica de La Plata (INIBIOLP), Universidad Nacional de La Plata, Calle 60 y 120 s/n, 1900 La Plata, Argentina

3 Division of Surgery and Interventional Science, University College London, London, UK

4 The School of Life Sciences, University of Essex, Colchester CO4 3SQ, UK

\author{
Abbreviations \\ ALA 5-Aminolevulinic acid \\ FBS Foetal bovine serum \\ MTT (3-[4,5-Dimethylthiazol-2-yl]-2,5-diphenyltetrazo- \\ liumbromide) \\ PDT Photodynamic therapy \\ PpIX Protoporphyrin IX \\ PBS Buffer phosphate
}

\section{Introduction}

Photodynamic therapy (PDT) is an effective alternative for the treatment of accessible lesions based on the ability of a photosensitiser (PS) to accumulate preferentially in the target cell. After PS administration, the lesion is illuminated employing light of an appropriate wavelength that activates the molecule, thus generating generates reactive oxygen species and inducing the destruction of the diseased tissue $[2,3]$ 
The natural pro-photosensitiser 5-aminolevulinic acid (ALA), when administered topically or systemically is capable of biosynthesising the endogenous PS Protoporphyrin IX $[4,5]$. ALA-PDT is increasingly being used clinically in dermatologic [6] and non-dermatologic malignancies (Casas, 2020). ALA was approved by the FDA and the EMA for the treatment of actinic keratosis and for intracranial use to aid in the surgery of high-grade gliomas [7].

Optimal accumulation and localization in target tissues remain a problem in the clinical management of PDT. One way to reduce this deficiency is the development of dendrimeric drug carriers that show appreciable ALA release, facilitating subsequent PpIX biosynthesis [8]. The dendrimers are hyperbranched polymers that are linked to different drugs, offering the advantage of having a defined structure, size, and load [9]. The added groups confer better solubility, cell targeting, and other biological effects. The main advantage of the use of dendrimers is the capacity to deliver a high drug payload by multiple binding of the desired molecules to the dendrimer [10]. Considering that ALA is a small molecule, it can be attached to macromolecules, to increase its delivery to the target cells. In our previous studies, we have demonstrated that ALA dendrimers can deliver ALA to cells and induce PpIX synthesis. The dendrimers of ALA hold ester bonds to ALA that inside the cells are cleaved and release ALA, inducing the production of PpIX [1]. We have previously designed and evaluated a series of novel ALA dendrimers, containing 3 to 18 ALA residues. The most promising were 6m-ALA and 9m-ALA, with similar performance in PAM212, LM3, Raw 264.7 and Hmec-1 cell lines [1,9].

Atherosclerosis is an inflammatory disease distinguished by the accumulation of LDL in the arterial vessels. When the condition progresses the so-called atherosclerotic plaques provokes a reduction of the arterial lumen. The plaque break induces acute coronary syndrome, with the consequent platelet activation, thrombus formation, and obstruction of the coronary arteries. Therapeutic strategies aimed at stabilising the vulnerable plaques or reducing its lipid content are desired [11].

All of the current interventions for the treatment of occlusive atherosclerosis are likely to induce restenosis at a later stage. Restenosis involves the narrowing of the luminal space due to neointimal hyperplasia and constrictive remodelling [12]. Among the alternatives to prevent restenosis, PDT is an exciting alternative since the treatment can control the inflammatory cells, promote vascular healing and has the potentiality to remove the plaque either partially or entirely [13]. The affinity of photosensitisers, such as porphyrins for atherosclerotic plaques, has extensively been reported $[14,15]$. Selective uptake of the PS in the plaques was ascribed to its high lipid content, thus inducing strong interactions between the drug and LDL [16]. Photosensitisers such as Photofrin [17],
Motexafin lutetium [18] and Indocyanine green [13] among other PSs have been proposed to be used in the photodynamic treatment of atherosclerotic lesions.

ALA has also been employed for photodynamic treatment or inhibition of restenosis in rabbit and pig models [19-21]. Besides, nanoparticles of ALA have been employed in rabbit models as theranostic agents for atherosclerosis [22].

The most important event of vessel wall damage in atherosclerosis is the accumulation of oxidised lipids in low-density lipoproteins (OxLDL). Circulating monocytes infiltrate the plaque, and get arrested into the vessels due to endothelial activation. At a later stage, they move to the arterial wall, convert into macrophages, and take up OxLDL leading to the subsequent formation of foam cells, the main components of fatty streaks in vulnerable plaques [23].

The main cellular components of the atherosclerotic plaques are endothelial cells, smooth muscle cells, macrophage foam cells, and lymphocytes. The most widely used technique for in vitro obtention of macrophage foam cells involves the exposure of macrophages to oxidised LDL [24]. The scavenger receptor class A type 1 (SRA1) and fatty acid translocase cluster of differentiation 36 (FAT/CD36) [25], has been implicated in the uptake of oxidised LDLs in macrophages. We have previously reported that the increased expression of FAT/CD36 in human THP1 monocytes is a marker of the transformation of macrophages to foam cells [26].

We have previously shown that ALA dendrimers containing 6 or 9 ALA molecules (so-called 6m-ALA and 9m-ALA) have been more selectively incorporated in murine Raw 264.7 macrophages after endocytosis uptake as compared to endothelial cells. PpIX synthesis in these macrophages were 6 and 4.6 times higher when they were exposed to $6 \mathrm{~m}$-ALA ad 9m-ALA as compared to the endothelial HMEC-1 cells, showing a preferential uptake of ALA dendrimers by the macrophages. It was hypothesised that the mechanism of uptake of the dendrimers mediated by caveolae-mediated endocytosis was responsible for the macrophage selectivity [1].

The present work aimed to study the selectivity of the ALA dendrimer 6m-ALA for the Raw 264.7 foam cells as compared to the endothelial HMEC-1 cells in a co-culture model. We have also evaluated the response of both cell types to photodynamic treatment mediated by ALA dendrimers and the involvement of apoptosis as the cell death mechanism.

\section{Materials and methods}

\subsection{Chemicals}

ALA and MTT were obtained from Sigma Chem Co, and $6 \mathrm{~m}$-ALA was provided by ChemPharm-Research, UK. The 
dendrimer 6m-ALA (Fig. 1) was synthesised as described previously [9].

\section{Cell lines}

Raw 264.7 macrophages (ATCC, Manassas, VA, USA) were grown in DMEM containing high glucose and pyruvate, supplemented with $2 \mathrm{mM}$ L-glutamine, $40 \mu \mathrm{g} / \mathrm{ml}$ gentamycin and $5 \%$ FBS.

HMEC-1 human endothelial cells were generously provided by Dr Ades (Centers for Disease Control and Prevention, Atlanta, USA) [27]. The cells were grown in RPMI 1640 medium, supplemented with $1 \mu \mathrm{g} / \mathrm{ml}$ hydrocortisone, $15 \%$ fetal bovine serum, $10 \mathrm{ng} / \mathrm{ml} \mathrm{hEGF}$, and $40 \mu \mathrm{g} / \mathrm{ml}$ gentamycin. Cells were used $24 \mathrm{~h}$ after plating and were grown at $37{ }^{\circ} \mathrm{C}$ and $5 \% \mathrm{CO}_{2}$.

\subsection{Isolation of LDL and preparation of oxidised LDL (OxLDL)}

The LDL fraction was isolated from plasma from healthy human volunteers as described previously [28].

To obtain OxLDL, the isolated LDLs were treated with copper sulphate as previously described in Ledda et al. [26]. The preparations were then sterilised by ultrafiltration through $22 \mu \mathrm{m}$ membranes, and stored under a nitrogen atmosphere. LDLs of medium oxidation degree were employed.

\subsection{Foam cell obtention}

Raw 264.7 macrophages were treated for different times with OxLDL at a concentration of $100 \mu \mathrm{g}$ protein $/ \mathrm{ml}$ in DMEM medium containing 5\% serum and then checked for FAT/ CD36 expression.

\subsection{Quantitative real-time PCR}

The expression of FAT/CD36 was quantified by RT-PCR after exposure to Raw 264.7 to OxLDL as described previously [26].

\subsection{PDT treatment}

Cells were exposed to ALA or 6m-ALA and $3 \mathrm{~h}$ in medium without FBS and afterwards, they were illuminated. Immediately, the medium was changed for complete medium, and the cells were incubated for $19 \mathrm{~h}$ to let photodamage occur. Phototoxicity was documented by the MTT assay [29]. MTT (3-[4,5-dimethylthiazol-2-yl]-2,5-diphenyltetrazoliumbromide) solution was added to the cells at $0.5 \mathrm{mg} / \mathrm{ml}$, and the cells were incubated at $37^{\circ} \mathrm{C}$ for $1 \mathrm{~h}$. The medium was withdrawn, DMSO was added to the formed formazan crystals, and the absorbance was read at $560 \mathrm{~nm}$ in an Epoch microplate reader (BioTek, USA).

\subsection{Light source}

We employed an array of 2 fluorescent lamps (Osram L $18 \mathrm{~W} / 827)$ (400 to $700 \mathrm{~nm}$ range with the highest radiant power at $600 \mathrm{~nm}$ ). The resulting power density was $0.5 \mathrm{~mW} /$ $\mathrm{cm}^{2}$ (Field Master power meter, LM3 HTP sensor, Coherent Inc., USA). The cells were illuminated from below and placed at a distance of $14 \mathrm{~cm}$ from the lamps.

\subsection{Porphyrin extraction}

Intracellular porphyrins were extracted with $\mathrm{HCl}$ as described previously [30] and quantified fluorimetrically in a Perkin Elmer LS55 spectrofluorimeter $\left(\lambda_{\mathrm{ex}}=406 \mathrm{~nm}\right.$, $\lambda_{\mathrm{em}}=604 \mathrm{~nm}$ ). Extracellular porphyrins were quantified by the addition of $\mathrm{HCl}$ to the media. PpIX (Frontier Scientific, Logan, USA) was employed as a standard [30].
Fig. 1 Structures of ALA and 6m-ALA dendrimer
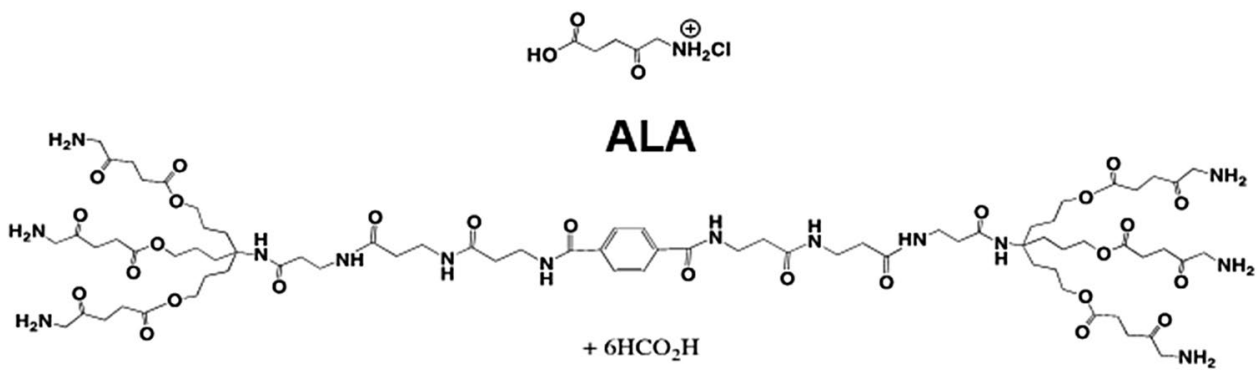

6m-ALA 


\subsection{Co-cultures}

Raw $264.7\left(1.5 \times 10^{4}\right.$ cells $)$ were transformed to foam cells during $12 \mathrm{~h}$ and afterwards, HMEC- $1\left(2.5 \times 10^{4}\right.$ cells $)$ were plated together in the medium for endothelial cells described above and incubated for a further $24 \mathrm{~h}$ until the experiments were performed.

\subsection{Cell morphology}

Foam cells, HMEC-1 and co-cultures were grown on coverslips during $24 \mathrm{~h}$ were treated with PDT mediated by $6 \mathrm{~m}$-ALA. Cells were fixed with $4 \%$ paraformaldehyde, washed with PBS, and stained with $0.5 \%$ crystal violet. Images were acquired with an Olympus microscope with a $20 \mathrm{X}$ objective.

\subsection{Porphyrin visualisation by fluorescence microscopy}

Foam cells, HMEC-1 cells, and co-cultures were grown on coverslips were exposed to ALA or 6m-ALA during $3 \mathrm{~h}$. Porphyrins were observed by fluorescence microscopy after mounting of the coverslips on PBS-DABCO mounting media. Microscopic observation and photography were performed with an Olympus microscope BX51, equipped with a mercury lamp and a green filter. Brightfield images were also documented. ImageJ 1.52i software was also employed to obtain quantitative values by measuring fluorescence intensity for the red channel. Briefly, a fluorescence value was obtained for every optical section of the analysed image, and then the values from the different sections were added up to obtain a single value for each image.

\subsection{Analysis of apoptosis rate by Annexin V-FITC/ Propidium iodide assay}

Nineteen hours after treatment, the percentage of apoptotic/necrotic cells was assessed using a standard flow cytometry Annexin-V-FITC binding assay (Thermo Fisher Scientific, USA) according to manufacturer's instructions. Annexin V and Propidium iodide (PI) fluorescence were measured in a BD FACSCalibur flow cytometer (Becton Dickinson, San Jose, CA, USA). Data were processed using FlowJo 10.0.7 software. 2.8.

\subsection{Statistical analysis}

Three experiments carried out per duplicates were performed. Statistical analysis of the results was made by a two-tailed Student's $t$ test. $p$ values $<0.05$ were considered significant.

\section{Results}

For the determination of foam cells formation, we analysed the OxLDL (FAT/CD36) receptor in Raw 264.7 cells exposed to Ox-LDL (Fig. 2). From $8 \mathrm{~h}$ onwards, the expression was significantly higher than the control, and thus, these macrophages can be considered foam cells. The increased receptor expression remained high for at least $24 \mathrm{~h}$ after withdrawal of Ox-LDL According to previous work of our group, the macrophages exposed to OxLDL also exhibit lipid accumulation resembling foam cells [31].

Raw 264.7 macrophages and foam cells were incubated with ALA, and their porphyrin synthesis and response to PDT were evaluated (Fig. 3). Both cell types did not differ significantly between them in both experiments. Equal amounts of extracellular porphyrins are released to the medium in Raw 264.7 macrophages and foam cells after 6m-ALA exposure (data not shown).

Cellular porphyrin production from ALA and ALA dendrimer was evaluated in the foam cells and HMEC-1 cells (Fig. 4). In both cell types, employing low sub-plateau concentrations $(0.05 \mathrm{mM})$, porphyrin synthesis induced by the dendrimers is significantly higher than ALA. At plateau values $(1 \mathrm{mM})$, tetrapyrrole production from ALA does not differ from that of the dendrimer both in foam cells and in HMEC-1 cells, although it is worth remarking that the amount of tetrapyrroles from both compounds is higher in the foam cells.

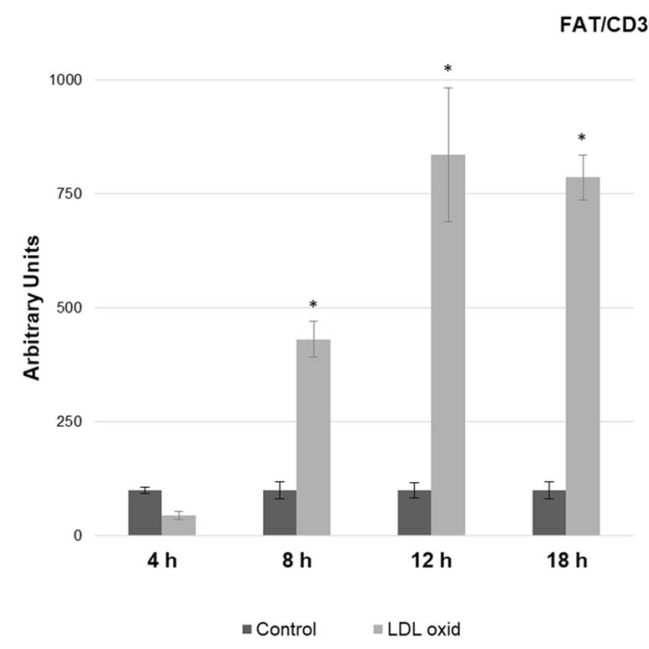

Fig. 2 Ratio of FAT/CD36 expression in foam cells. Quantification of FAT/CD36 was carried out by RT-PCR after different time exposure of Raw 264.7 macrophages to Ox-LD. The average of three experiments is shown. ${ }^{*} p<0.01$ as compared to the control 

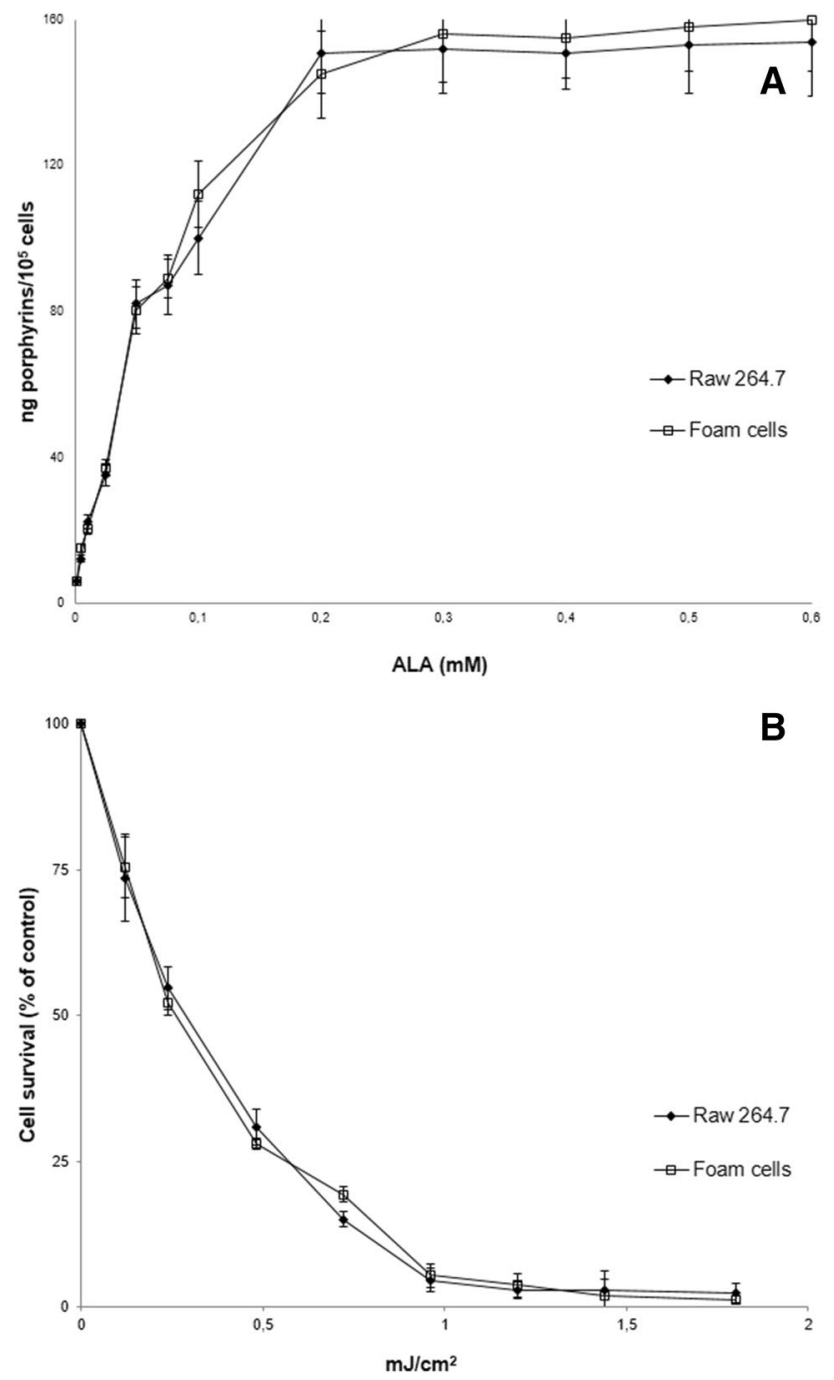

Fig. 3 Porphyrin production after ALA exposure and response to ALA-PDT in Raw 264.7 macrophages and foam cells. Cells were treated $3 \mathrm{~h}$ with increasing concentrations of ALA. a Porphyrin were extracted from the cells and quantified fluorometrically. b Cells were treated $3 \mathrm{~h}$ with $1 \mathrm{mM}$ ALA and PDT was carried out employing increasing light doses, and cell viability was determined

Figure 5 shows PDT response mediated by $6 \mathrm{~m}$-ALA of foam cells and HMEC-1 cells. The foam cells were markedly more responsive to PDT under the plateau $(0.05 \mathrm{mM})$ conditions evaluated. LD50s were 0.3 and $1.1 \mathrm{~J} / \mathrm{cm}^{2}$ for foam cells and HMEC-1, respectively, in line with a lower porphyrin production in the endothelial cells (see Fig. 4). These data suggest a 3.8 times higher response of the foam as compared to the endothelial cells. It is important to mention the differences between the slopes of both curves; in foam cells, $100 \%$ cell death is obtained at low light doses, while in HMEC-1 cells it was not possible to achieve absolute cell death in the range of light doses studied. This difference clearly shows the higher sensitivity of foam cells for PDT. On the other hand, ALA-PDT treatment under these conditions induced

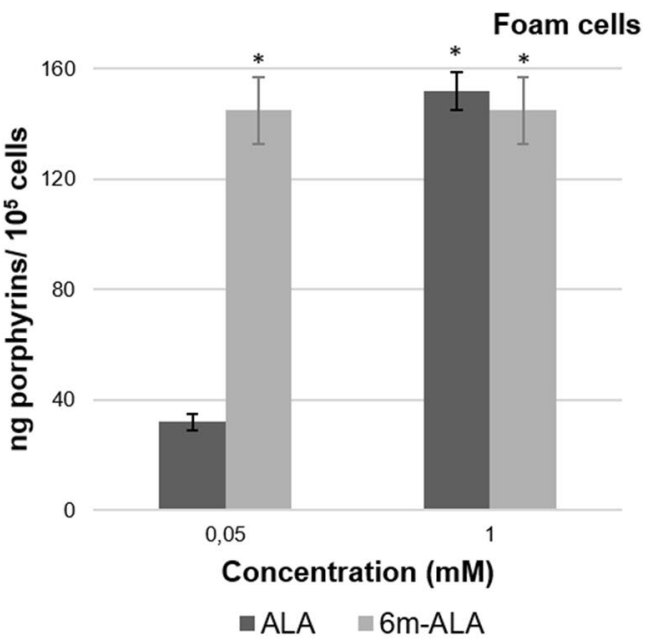

HMEC-1

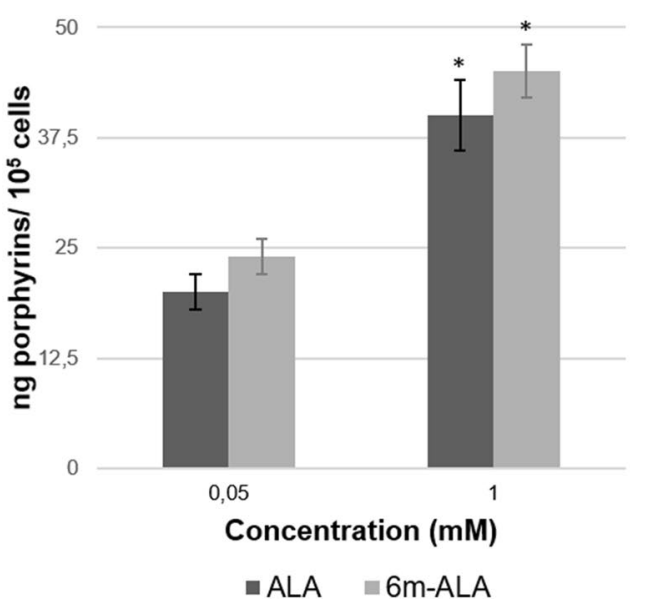

Fig. 4 Porphyrin production induced by ALA and ALA dendrimers in foam and endothelial cells. Foam cells and HMEC-1 cells were treated $3 \mathrm{~h}$ with 0.05 or $1 \mathrm{mM}$ of ALA or ALA dendrimers. Porphyrins were quantified fluorometrically. $* p<0.05$ as compared to $0.05 \mathrm{mM}$ ALA

no response in either cell line due to no induction of porphyrins at $0.05 \mathrm{mM}$ concentration (data not depicted).

Cell morphology of the control co-cultures shows that both cell types can duplicate and co-exist under the established conditions, and they can be distinguished using morphology criteria (Fig. 6). Whereas foam cells are small and rounded, the HMEC- 1 are tapered and exhibit more spreading on the surface. After PDT treatment employing $6 \mathrm{~m}$-ALA, the proportion of foam cells is impaired upon increasing the light dose, whereas the endothelial cells are relatively refractory to the treatment.

Fluorescence microscopy of porphyrins synthesised from ALA and 6-mALA at a concentration of $0.05 \mathrm{mM}$ was analysed in HMEC-1, foam cells, and co-cultures (Fig. 7). The corresponding bright-field images were also documented to distinguish both cell types based on the morphology. An 
Fig. 5 Response of foam and HMEC-1 cells to PDT employing $6 \mathrm{~m}$-ALA. Cells were treated $3 \mathrm{~h}$ with $0.05 \mathrm{mM} 6 \mathrm{~m}$-ALA and then, PDT was carried out and cell viability was determined
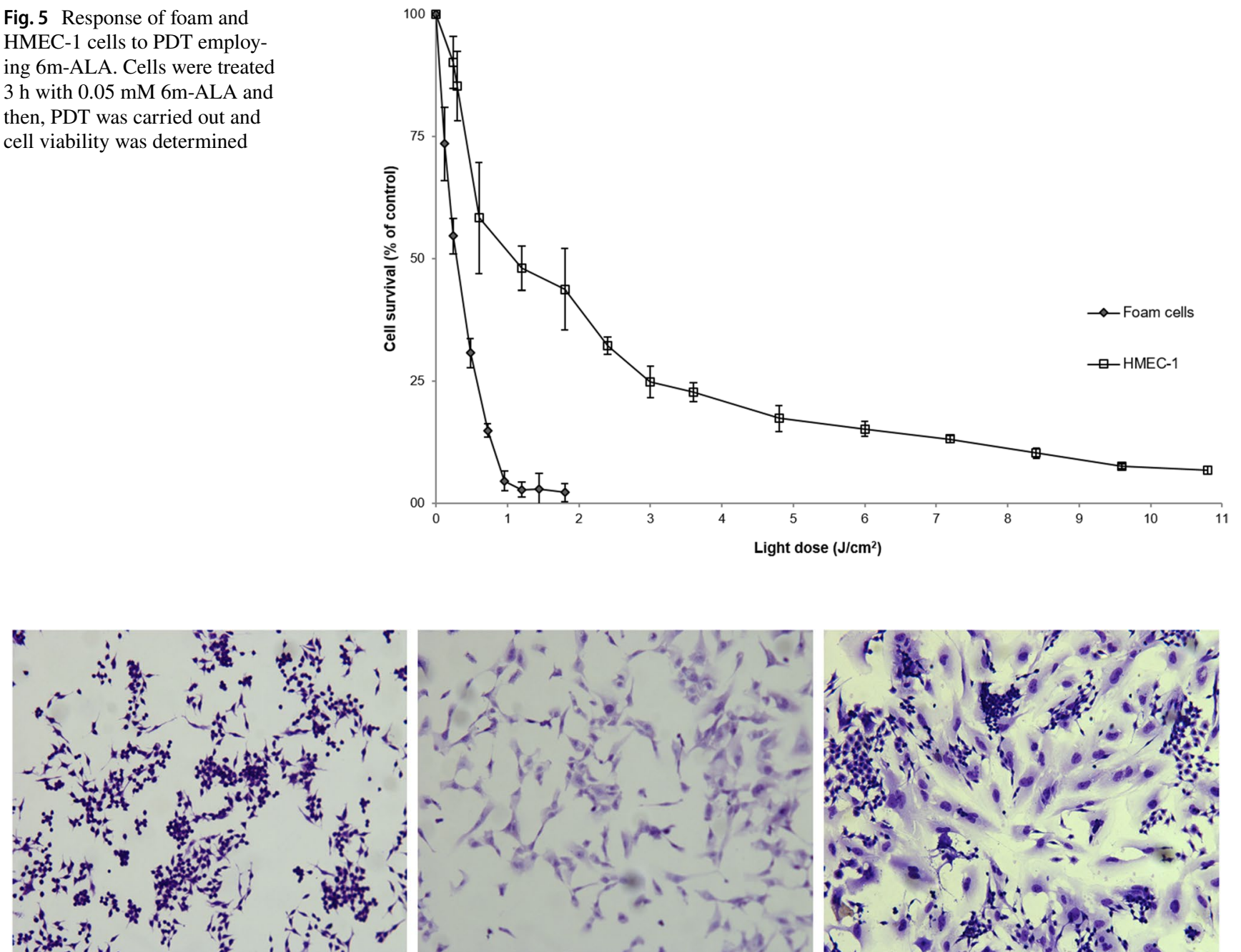

Foam cells

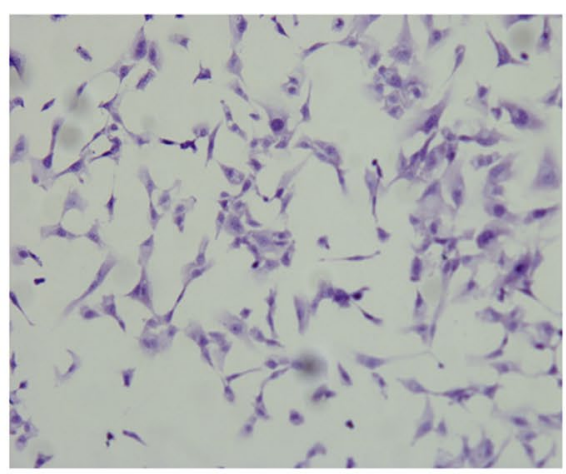

HMEC-1

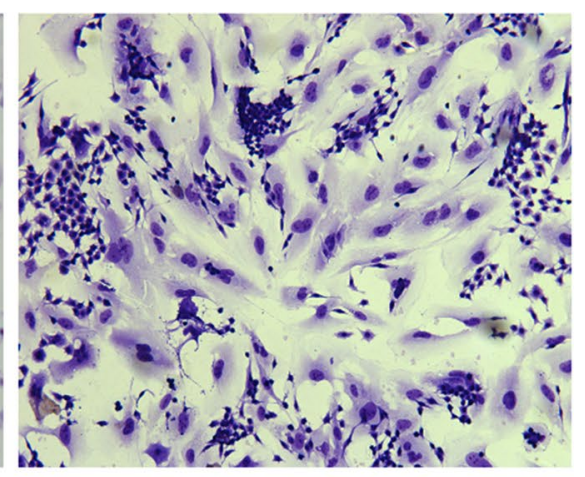

Co-culture

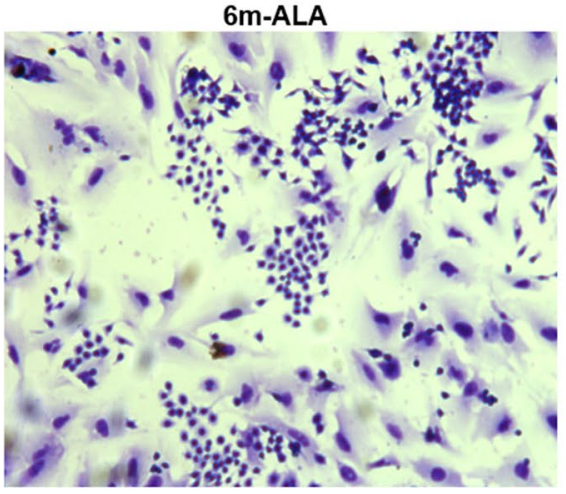

Co-culture

$6 \mathrm{~m}-\mathrm{ALA}+0.12 \mathrm{~J} / \mathrm{cm}^{2}$

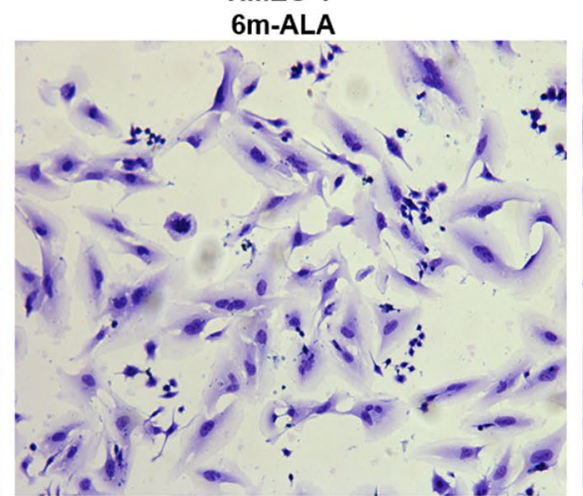

Co-culture

$6 \mathrm{~m}-\mathrm{ALA}+0.24 \mathrm{~J} / \mathrm{cm}^{2}$
6m-ALA

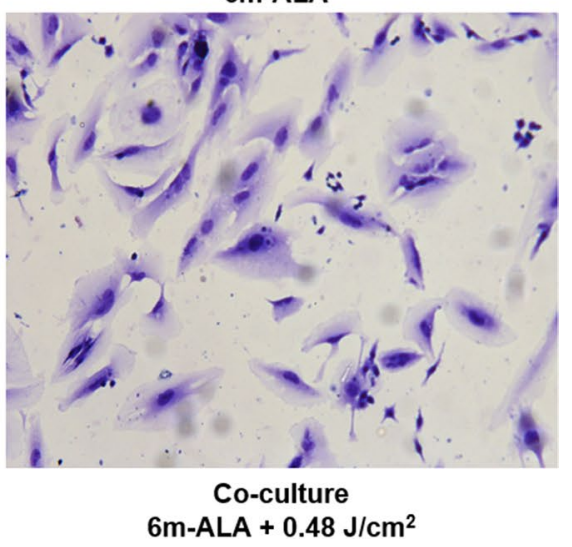

Fig. 6 Co-culture of foam cells and HMEC-1 cells treated with $6 \mathrm{~m}$-ALA-PDT. Crystal violet staining. Magnification $\times 20$. Cells were incubated with $0.05 \mathrm{mM} 6 \mathrm{~m}$-ALA during $3 \mathrm{~h}$ and then irradiated at

intense red fluorescence can be distinguished in the foam cells exposed to 6m-ALA but not to ALA, whereas HMEC-1 cells exhibit basal autofluorescence intensity. different light doses and stained $19 \mathrm{~h}$ later. The images are representative of 3 independent experiments

To target atherosclerotic plaque, the type of triggered death is critical. Necrosis would lead to rupture of the plaque, and thus, the induction apoptotic cell death is 


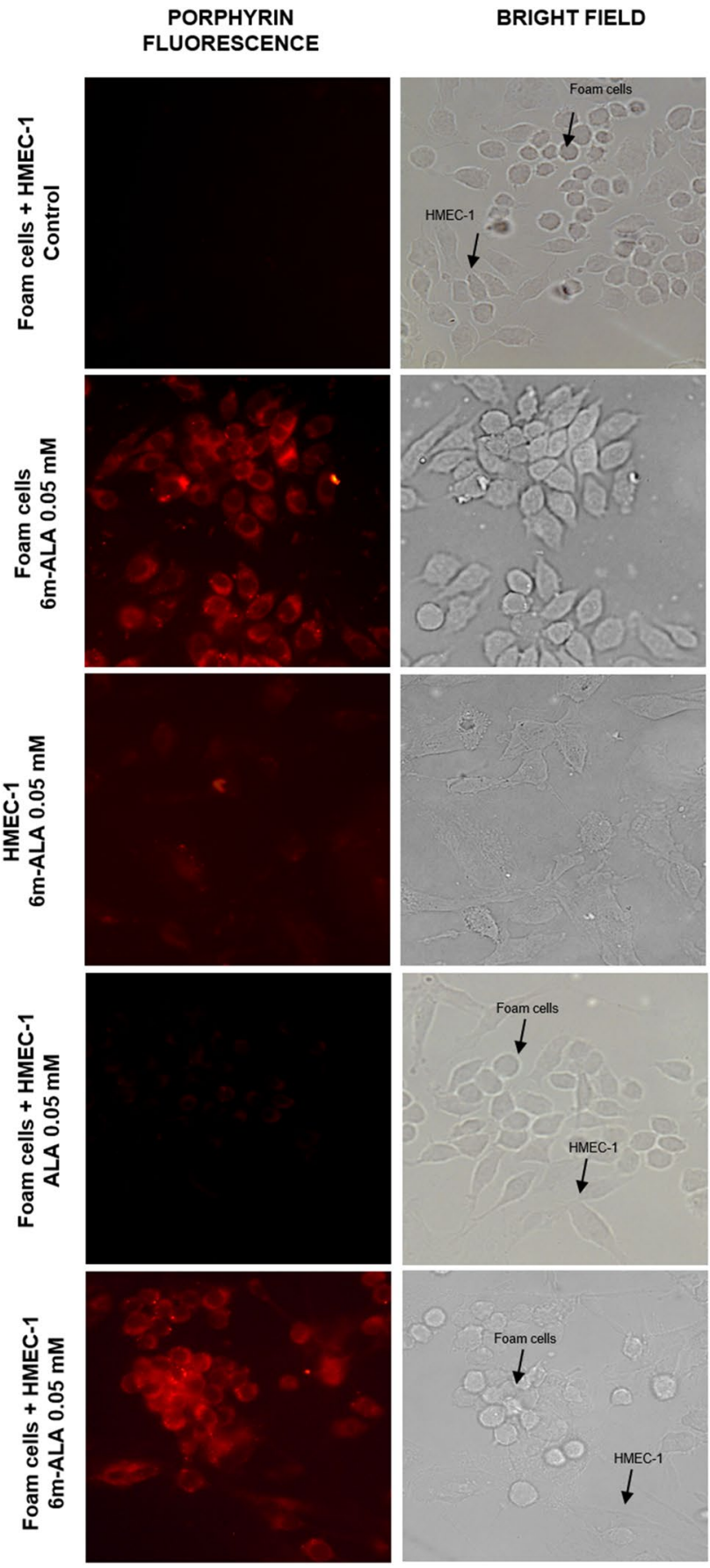

Fig. 7 Fluorescence microscopy of foam cells and HMEC-1 cells treated with ALA and 6m-ALA. Foam cells and HMEC-1 cells were exposed to $0.05 \mathrm{mM}$ ALA or $6 \mathrm{~m}$-ALA for $3 \mathrm{~h}$. a Micrographs were taken after fluorescence microscopy inspection. Magnification $\times 40$. b Qualitative porphyrin detection expressed in arbitrary units

desirable in any potential treatment. Therefore, an analysis of apoptosis and necrosis was performed employing the annexin V-FITC/PI flow cytometry assay (Fig. 8).

It can be noticed that PDT mediated by $6 \mathrm{~m}$-ALA impairs slightly the percentage of HMEC-1 viable cells $(99.4 \%$ viable control cells vs $85.9 \%$ 6m-ALA-PDT treated with $240 \mathrm{~mJ} / \mathrm{cm}^{2}$ and $83.9 \%$ in the $720 \mathrm{~mJ} / \mathrm{cm}^{2}$ treated group). On the other hand, foam cells treated under the light conditions mentioned above, show a markedly high percentage of cell death, that is 50 and $70 \%$ of apoptotic cells at 240 and $720 \mathrm{~mJ} / \mathrm{cm}^{2}$ respectively. No necrosis is induced in any condition.

\section{Discussion and conclusion}

In previous work, we have found that ALA dendrimers containing 9 or 6 ALA residues were more selective than ALA for the macrophages Raw 267.4 as compared to the HMEC-1 endothelial cell line. The high ability of macrophages to internalise molecules maybe explaining the selectivity of the hyperbranched molecules containing ALA towards them [1], suggesting that PDT mediated by ALA dendrimers is a promising tool to target atheromatous plaques selectively. Moreover, the dendrimer 6m-ALA was chosen to perform this study since it induced the highest porphyrin macrophage: endothelial cell ratio [1].

Macrophages play essential roles in several diseases; therefore a specific strategy to destroy them may have encouraging therapeutic advantages [32]. It has been previously addressed that the ability of PDT to induce macrophages selective destruction can be employed in the treatment of diseases such as cancer [33-35], detection of atherosclerotic plaques [36], autoimmune diseases [37] and infections [38, 39].

Comparison of porphyrin synthesis from 6m-ALA showed no differences between macrophages and foam cells. It suggests that higher lipid load does not affect neither porphyrin synthesis nor retention in the foam cells. Moreover, the rate of cell death after PDT is not different between Raw 264.7 macrophages and foam cells. The fact that equal amounts of porphyrins are released to the medium in Raw 264.7 macrophages and foam cells after 6m-ALA exposure reinforces the hypothesis that LDL load does not particularly retain PpIX into the cells.

Cocultures of foam and endothelial cells is a model to mimic better the scenario of the atheromatous plaque. We demonstrated that there are no significant differences between porphyrins synthesised from macrophages and foam cells, being the maximum porphyrin synthesis $152.2 \pm 1.4 \mathrm{ng}$ porphyrins $/ 10^{5}$ cells for Raw 264.7 and $154.8 \pm 5.8$ ng porphyrins $/ 10^{5}$ cells for foam cells, and both cell types present LD50s in the range of $0.3 \mathrm{~J} / \mathrm{cm}^{2}$ and LD100 employing light doses lower than $2 \mathrm{~J} / \mathrm{cm}^{2}$.

HMEC-1 endothelial cells synthesised from ALA dendrimers a markedly lower amount of porphyrins as compared to foam cells. The plateau valued is reached at $42.7 \pm 2.5 \mathrm{ng} / 10^{5}$ cells, which leads to a modest response to 
Fig. 8 Mechanism of cell killing after $6 \mathrm{~m}$-ALA-PDT in foam and HMEC-1 cells. Quadrant statistics: necrotic cells in Q1, late apoptotic cells in Q2, early apoptotic cells in Q3 and viable cells in Q4. a Flow cytometry analysis of foam cells $y$ HMEC-1 treated with $0.05 \mathrm{mM}$ 6m-ALA-PDT. b Percentage of cells in each phase of the cell cycle. The chart shows a representative of 3 independent experiments
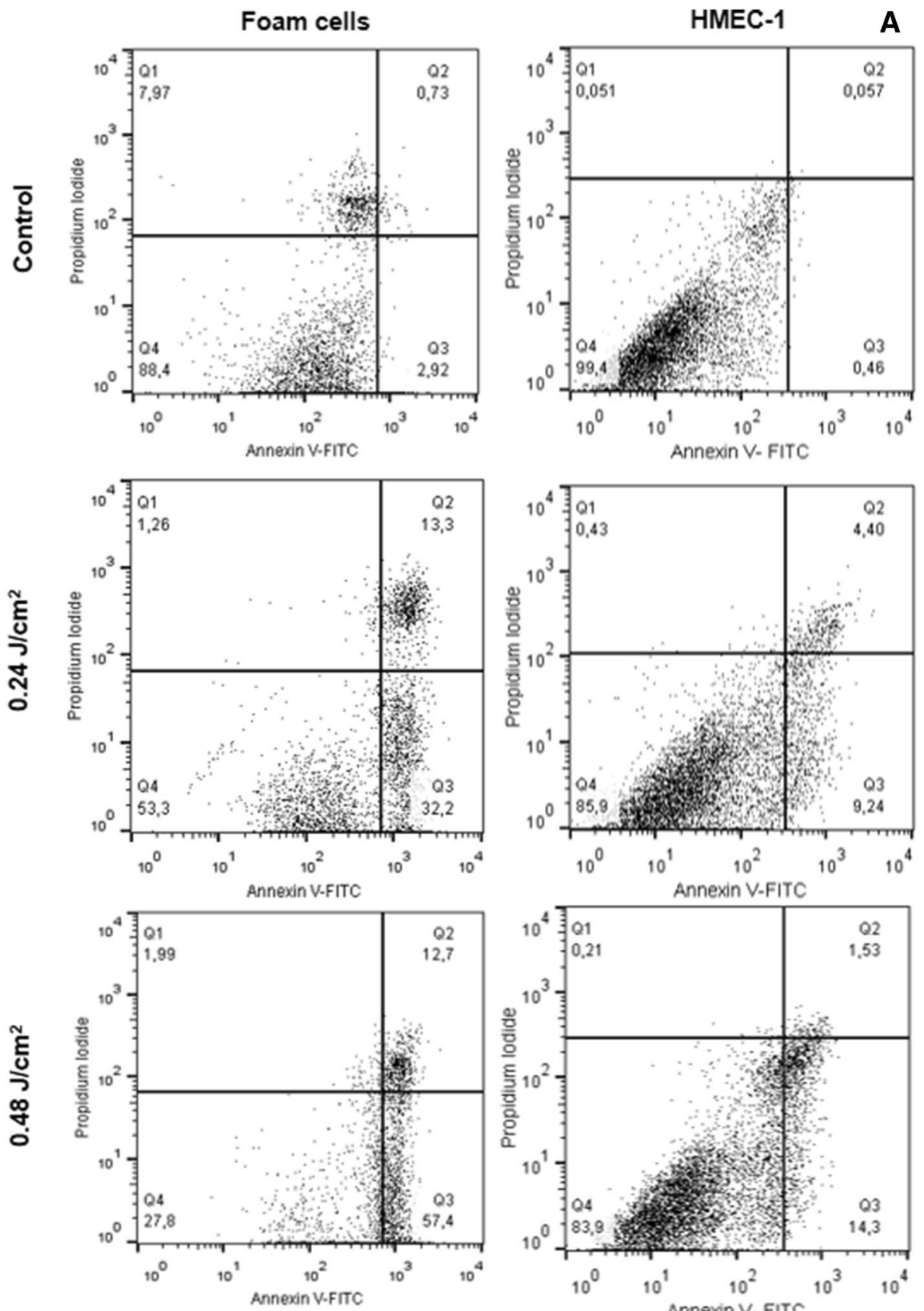

Foam cells
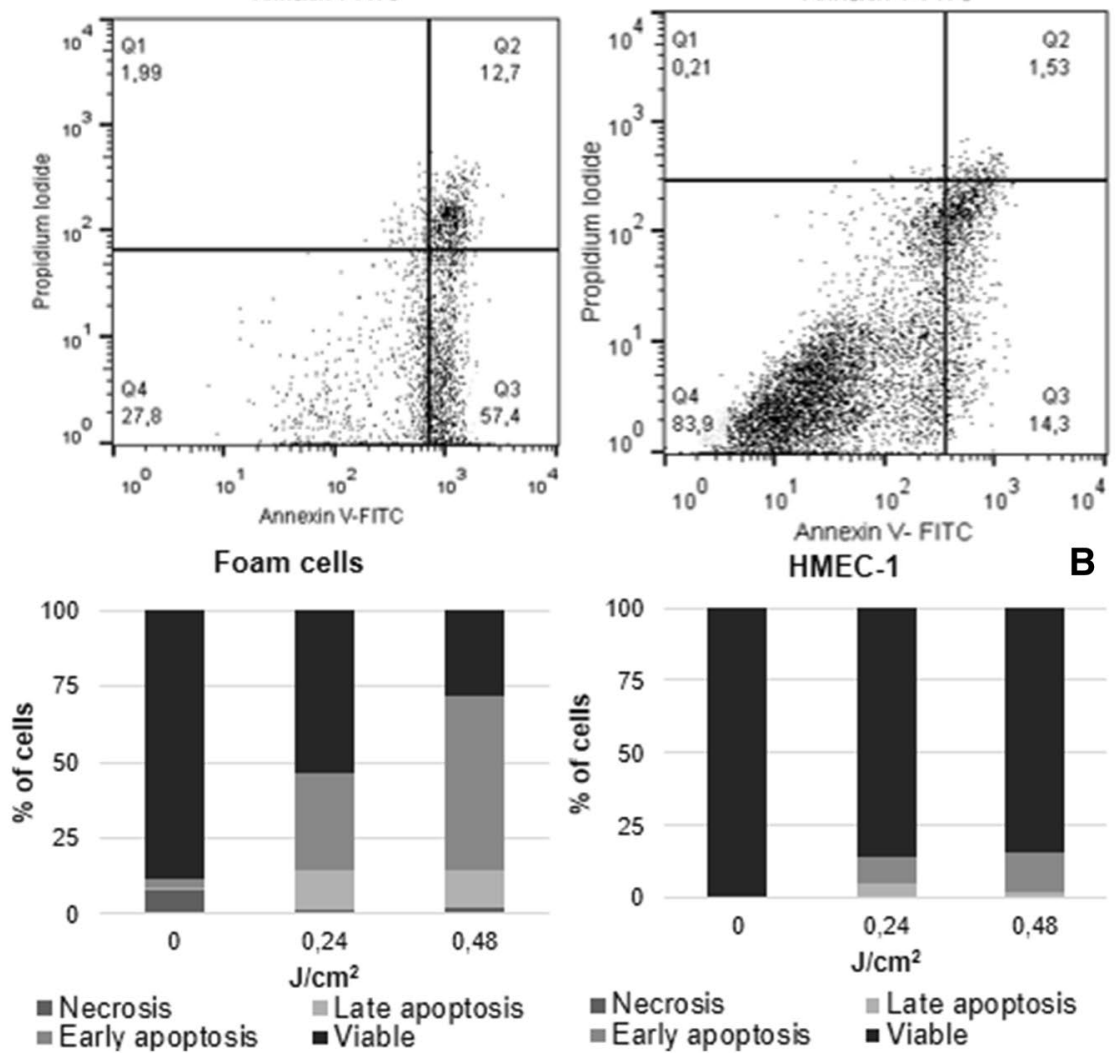

Necrosis

E Early apoptosis
Late apoptosis - Viable 
PDT, with an LD50 of $1.1 \mathrm{~J} / \mathrm{cm}^{2}$, and it was not possible to reach the LD100 in the range of light doses used $(0-11 \mathrm{~J} /$ $\mathrm{cm}^{2}$ ). As we demonstrated in a previous work, dendrimers do not enhance PpIX production from ALA in HMEC-1 cells even at low concentrations, and we ascribe this to their low endocytic ability [1]. In this context, the foam cells should be destroyed by therapy, while the endothelial cells are not damaged.

Co-cultures are useful models to investigate heterotypic cell-cell interactions and physical contact, and the impact of autocrine and/or paracrine intercommunications on cell function [40]. Zuniga et al. [41] employed co-cultures of vascular smooth muscle cells and macrophages to study the interaction between the cell types in atherosclerotic plaques. Endothelial cell/macrophage co-cultures have been employed as models of other diseases [42].

In the present work, we employed a co-culture model of foam cells and endothelial cells to get a closer approach to the atherosclerotic plaques considering that the heterotypic interactions between both cell types could lead to differential responses to the photodynamic injury as compared to the isolated cell components.

We have also extended our studies to foam cells, and cocultures of foam and endothelial cells, showing once more that the dendrimers are more effective as compared to ALA at low equimolar concentrations. Porphyrin synthesis from ALA dendrons and dendrimers was also efficient in other tumour and non-tumour cell types [1, 10, 43, 44].

We found that the employment of ALA dendrimers induces quite selective production of porphyrins in the foam cells, securing the specificity of the photodamage without damaging the intima endothelial cells. Those results show that the highest sensitivity of foam cells to PDT is not modified by the interaction between both cell lines in the coculture and that dendrimers synthesise more porphyrins in foam cells than in endothelial cells regardless of being co-cultured.

ALA-PDT applied to the murine macrophage J-774A.1 cells induced impaired viability as well as an increase in reactive oxygen intermediates and TNF- $\alpha$ release and diminished $\mathrm{Nf}-\kappa \mathrm{B}$ p50 and $\mathrm{p} 65$, Il-1 $\beta$ production [45].

Jenkins et al. [19] have already shown different kinetics of porphyrins formation in each cell type forming the atherosclerotic plaque. Moreover, the different layers of the arteria show different PpIX fluorescence peaks.

Other nano vehicles of ALA such as gold nanoparticles functionalised with polyethylene glycol were orally given to rodents to be used as theranostic non-invasive agents for atherosclerosis. The PpIX fluorescence measured in blood and faeces was a measured of the nanoparticle incorporated into the plaques [22].

In our model, endothelial cells at $3 \mathrm{~h}$ after exposure to the ALA dendrimers, synthesised much lower porphyrins as compared to the foam cells. However, it must be remarked that the porphyrin peaks may be obtained at different time exposure to the compounds and that the illumination time would be pivotal in the outcome of the treatment.

In opposition to necrosis, apoptosis is a commanded process, which is beneficial to happen instead of necrosis, since no inflammation occurs [46]. In this work, we reported that that the foam cells killed by PDT mediated by ALA dendrimers are killed mediated the apoptosis pathway, which is an encouraging result.

Since the discovery of the clinical potential of ALAPDT, progress has been made in the development of simple derivatives of ALA that have improved bioavailability and stability compared to ALA itself. The ALA methyl ester is now a mainstay for topical ALA-PDT in the clinic, and the hexyl ester is widely accepted for use in photodiagnosis [47]. Taking into account that the development of effective platforms for the systemic delivery of ALA remains to be resolved, as well as delving into new applications in addition to cancer such as photoangioplasty, our results encourage the use of ALA dendrimers in the photodynamic treatment of obstructive cardiovascular diseases to be combined with current therapies to aid in the management of vulnerable plaques. Due to selective localisation in foam cells, we foresee applications of the dendrimer $6 \mathrm{~m}$-ALA as a theranostic agent. However, further studies extrapolating these results to a clinical setting are needed to confirm that $6 \mathrm{~m}$-ALA is promising in photoangioplasty.

Acknowledgements Work at CIPYP was supported by grants from CONCET (PIP 0237, to AC) and ANPCyT (PICT 2014-0727, to AC). MC thanks INC for a student fellowship. GC thanks CONICET for a doctoral fellowship. The authors are grateful to Vanina Ripoll for her technical support.

Author Contributions GD and AC conceived the biological experiments and wrote the main text. MC, DS, GC and GD carried out the biological experiments. MG carried out the isolation of LDL, preparation of OxLDL AM and SB provide the dendrimer 6m-ALA. All authors reviewed the manuscript.

\section{Declarations}

Conflict of interest There are no conflicts to declare.

\section{References}

1. Rodriguez, L., Vallecorsa, P. D., Battah, S., Di Venosa, G. M., Mamone, L. A., Saenz, D. A., Gonzalez, M. C., Batlle, A. J., MacRobert, A. J., \& Casas, A. G. (2015). Aminolevulinic acid dendrimers in photodynamic treatment of cancer and atheromatous disease. Photochemical and Photobiological Sciences, 14, 1617-1627.

2. Dougherty, T. J., Kaufman, J. E., Goldfarb, A., Weishaupt, K. R., Boyle, D., \& Mittleman, A. (1978). Photoradiation therapy for the treatment of malignant tumors. Cancer Research, 38, 2628-2635. 
3. Agostinis, P., Berg, K., Cengel, K. A., Foster, T. H., Girotti, A. W., Gollnick, S. O., Hahn, S. M., Hamblin, M. R., Juzeniene, A., Kessel, D., Korbelik, M., Moan, J., Mroz, P., Nowis, D., Piette, J., Wilson, B. C., \& Golab, J. (2011). Photodynamic therapy of cancer: an update. CA A Cancer Journal for Clinicians, 61, 250-281.

4. Kennedy, J. C., Marcus, S. L., \& Pottier, R. H. (1996). Photodynamic therapy (PDT) and photodiagnosis (PD) using endogenous photosensitization induced by 5 -aminolevulinic acid (ALA): Mechanisms and clinical results. Journal of Clinical Laser Medicine and Surgery, 14, 289-304.

5. Fukuda, H., Casas, A., Chueke, F., Paredes, S., \& Batlle, A. M. C. (1993). Photodynamic action of endogenously synthesized porphyrins from aminolevulinic acid, using a new model for assaying the effectiveness of tumoral cell killing. International Journal of Biochemistry, 25, 1395-1398.

6. Wen, X., Li, Y., \& Hamblin, M. R. (2017). Photodynamic therapy in dermatology beyond non-melanoma cancer: an update. Photodiagnosis and Photodynamic Therapy, 19, 140-152.

7. Casas, A. (2020). Clinical uses of 5-aminolaevulinic acid in photodynamic treatment and photodetection of cancer: a review. Cancer Letters, 490, 165-173.

8. Zhou, T., Battah, S., Mazzacuva, F., Hider, R. C., Dobbin, P., \& Macrobert, A. J. (2018). Design of bifunctional dendritic 5-aminolevulinic acid and hydroxypyridinone conjugates for photodynamic therapy. Bioconjugate Chemistry, 29, 3411-3428.

9. Battah, S. H., Chee, C. E., Nakanishi, H., Gerscher, S., MacRobert, A. J., \& Edwards, C. (2001). Synthesis and biological studies of 5-aminolevulinic acid-containing dendrimers for photodynamic therapy. Bioconjugate Chemistry, 12, 980-988.

10. Battah, S., Balaratnam, S., Casas, A., O'Neill, S., Edwards, C., Batlle, A., Dobbin, P., \& MacRobert, A. J. (2007). Macromolecular delivery of 5-aminolaevulinic acid for photodynamic therapy using dendrimer conjugates. Molecular Cancer Therapeutics, 6 , 876-885.

11. Kou, J., Dou, D., \& Yang, L. (2017). Porphyrin photosensitizers in photodynamic therapy and its applications. Oncotarget, 8 , 81591-81603.

12. Roy, T., Forbes, T., Wright, G., \& Dueck, A. (2015). Burning bridges: Mechanisms and implications of endovascular failure in the treatment of peripheral artery disease. The Journal of Endovascular Therapy, 22, 874-880.

13. Houthoofd, S., Vuylsteke, M., Mordon, S., \& Fourneau, I. (2020). Photodynamic therapy for atherosclerosis. The potential of indocyanine green. Photodiagnosis and Photodynamic Therapy, 29, 101568.

14. Straight, R., Vincent, G., \& Hammond, E. (1986). Porphyrin retention and photodynamic treatment of diet induced atherosclerotic lesions in pig. Photodynamic therapy of tumors and other diseases. Padova: Libreria Progetto.

15. Eldar, M., Yerushalmi, Y., Kessler, E., Scheinowitz, M., Goldbourt, U., Ben Hur, E., Rosenthal, I., \& Battler, A. (1990). Preferential uptake of a water-soluble phthalocyanine by atherosclerotic plaques in rabbits. Atherosclerosis, 84, 135-139.

16. Hamblin, M. R., \& Luke Newman, E. (1994). New trends in photobiology. On the mechanism of the tumour-localising effect in photodynamic therapy. The Journal of Photochemistry and Photobiology B Biology, 23, 3-8.

17. Spokojny, A. M., Serur, J. R., Skillman, J., \& Richard Spears, J. (1986). Uptake of hematoporphyrin derivative by atheromatous plaques: Studies in human in vitro and rabbit in vivo. Journal of the American College of Cardiology, 8, 1387-1392.

18. Rockson, S. G., Lorenz, D. P., Cheong, W. F., \& Woodburn, K. W. (2000). Photoangioplasty: An emerging clinical cardiovascular role for photodynamic therapy. Circulation, 102, 591-596.

19. Jenkins, M. P., Buonaccorsi, G., MacRobert, A., Bishop, C. C. R., Brown, S. G., \& McEwan, J. R. (1998). Intra-arterial photodynamic therapy using 5-ALA in a swine model. European Journal of Vascular and Endovascular Surgery, 16, 284-291.

20. Jenkins, M. P., Buonaccorsi, G. A., Mansfield, R., Bishop, C. C. R., Bown, S. G., \& McEwan, J. R. (2000). Reduction in the response to coronary and iliac artery injury with photodynamic therapy using 5-aminolaevulinic acid. Cardiovascular Research, $45,478-485$.

21. Mansfield, R. J. R., Jenkins, M. P., Pai, M. L., Bishop, C. C. R., Bown, S. G., \& McEwan, J. R. (2002). Long-term safety efficacy of superficial femoral artery angioplasty with adjuvant photodynamic therapy to prevent restenosis. British Journal of Surgery, 89, 1538-1539.

22. De Oliveira Gonçalves, K., Da Silva, M. N., Sicchieri, L. B., De Oliveira Silva, F. R., De Matos, R. A., \& Courrol, L. C. (2015). Aminolevulinic acid with gold nanoparticles: A novel theranostic agent for atherosclerosis. The Analyst, 140, 1974-1980.

23. Moore, K. J., \& Tabas, I. (2011). Macrophages in the pathogenesis of atherosclerosis. Cell, 145, 341-355.

24. Sengupta, B., Narasimhulu, C. A., \& Parthasarathy, S. (2013). Novel technique for generating macrophage foam cells for in vitro reverse cholesterol transport studies. Journal of Lipid Research, 54, 3358-3372.

25. Collot-Teixeira, S., Martin, J., McDermott-Roe, C., Poston, R., \& McGregor, J. L. (2007). CD36 and macrophages in atherosclerosis. Cardiovascular Research, 75, 468-477.

26. Ledda, A., González, M., Gulfo, J., Díaz Ludovico, I., Ramella, N., Toledo, J., Garda, H., Grasa, M., \& Esteve, M. (2016). Decreased OxLDL uptake and cholesterol efflux in THP1 cells elicited by cortisol and by cortisone through $11 \beta$-hydroxysteroid dehydrogenase type 1. Atherosclerosis, 250, 84-94.

27. Ades, E. W., Candal, F. J., Swerlick, R. A., George, V. G., Summers, S., Bosse, D. C., \& Lawley, T. J. (1992). HMEC-1: establishment of an immortalized human microvascular endothelial cell line. The Journal of Investigative Dermatology, 99, 683-690.

28. Tricerri, A., Córsico, B., Toledo, J. D., Garda, H. A., \& Brenner, R. R. (1998). Conformation of apolipoprotein AI in reconstituted lipoprotein particles and particle-membrane interaction: Effect of cholesterol. Biochimica et Biophysica Acta (BBA) Lipids and Lipid Metabolism, 1391, 67-78.

29. Denizot, F., \& Lang, R. (1986). Rapid colorimetric assay for cell growth and survival. Modifications to the tetrazolium dye procedure giving improved sensitivity and reliability. The Journal of Immunological Methods, 89, 271-277.

30. Rodriguez, L., de Bruijn, H. S., Di Venosa, G., Mamone, L., Robinson, D. J., Juarranz, A., Batlle, A., \& Casas, A. (2009). Porphyrin synthesis from aminolevulinic acid esters in endothelial cells and its role in photodynamic therapy. The Journal of Photochemistry and Photobiology B Biology, 96, 249-254.

31. Toledo, J., Esteve, M., Grasa, M., Ledda, A., Garda, H., Gulfo, J., Ludovico, I. D., Ramella, N., \& Gonzalez, M. (2016). Data related to inflammation and cholesterol deposition triggered by macrophages exposition to modified LDL. Data in Brief, 8 , 251-257.

32. Demidova, T. N., \& Hamblin, M. R. (2004). Photodynamic therapy targeted to pathogens. International Journal of Immunopathology and Pharmacology, 17, 245-254.

33. Wahl, L., \& Kleinman, H. (1998). Tumor-associated macrophages as targets for cancer therapy. Journal of the National Cancer Institute, 90, 1583-1584.

34. Korbelik, M., \& Hamblin, M. R. (2015). The impact of macrophage-cancer cell interaction on the efficacy of photodynamic therapy. Photochemical and Photobiological Sciences, 14, 1403-1409.

35. Evans, S., Matthews, W., Perry, R., Fraker, D., Norton, J., \& Pass, H. I. (1990). Effect of photodynamic therapy on tumor necrosis 
factor production by murine macrophages. Journal of the National Cancer Institute, 82, 34-39.

36. Hamblin, M. R., Tawakol, A., Castano, A. P., Gad, F., Zahra, T., Ahmadi, A., Stern, J., Ortel, B., Chirico, S., Shirazi, A., Syed, S., \& Muller, J. E. (2003). Macrophage-targeted photodynamic detection of vulnerable atherosclerotic plaque. Lasers in surgery: Advanced characterization, therapeutics, and systems XIII (Vol. 4949, p. 466). Bellingham: SPIE.

37. Schmitt, F., Lagopoulos, L., Käuper, P., Rossi, N., Busso, N., Barge, J., Wagnières, G., Laue, C., Wandrey, C., \& Juillerat-Jeanneret, L. (2010). Chitosan-based nanogels for selective delivery of photosensitizers to macrophages and improved retention in and therapy of articular joints. Journal of Controlled Release, 144, 242-250.

38. Amer, A. O., \& Swanson, M. S. (2002). A phagosome of one's own: A microbial guide to life in the macrophage. Current Opinion in Microbiology, 5, 56-61.

39. Stafford, J. L., Neumann, N. F., \& Belosevic, M. (2002). Macrophage-mediated innate host defense against protozoan parasites. Critical Reviews in Microbiology, 28, 187-248.

40. Bogdanowicz, D. R., \& Lu, H. H. (2013). Multifunction co-culture model for evaluating cell-cell interactions (pp. 29-36). New York: Springer New York.

41. Zuniga, M. C., Raghuraman, G., \& Zhou, W. (2018). Physiologic levels of resistin induce a shift from proliferation to apoptosis in macrophage and VSMC co-culture. Surgery, 163(4), 906-911.
42. Tanabe, S. I., \& Grenier, D. (2009). Endothelial cell/macrophage cocultures as a model to study Streptococcus suis-induced inflammatory responses: RESEARCH ARTICLE. FEMS Immunology and Medical Microbiology, 55, 100-106.

43. Di Venosa, G. M., Casas, A. G., Battah, S., Dobbin, P., Fukuda, H., MacRobert, A. J., \& Batlle, A. (2006). Investigation of a novel dendritic derivative of 5-aminolaevulinic acid for photodynamic therapy. International Journal of Biochemistry and Cell Biology, $38,82-91$.

44. Casas, A., Battah, S., Di Venosa, G., Dobbin, P., Rodriguez, L., Fukuda, H., Batlle, A., \& MacRobert, A. J. (2009). Sustained and efficient porphyrin generation in vivo using dendrimer conjugates of 5-ALA for photodynamic therapy. Journal of Controlled Release, 135, 136-143.

45. Kawczyk-Krupka, A., Czuba, Z., Szliszka, E., Król, W., \& Sieroń, A. (2011). The role of photosensitized macrophages in photodynamic therapy. Oncology Reports, 26, 275-280.

46. Syed Abdul Rahman, S. N., Abdul Wahab, N., \& Abd Malek, S. N. (2013). In vitro morphological assessment of apoptosis induced by antiproliferative constituents from the rhizomes of Curcuma zedoaria. Evidence-Based Complementary and Alternative Medicine. https://doi.org/10.1155/2013/257108

47. Tewari, K. M., \& Eggleston, I. M. (2018). Chemical approaches for the enhancement of 5-aminolevulinic acid-based photodynamic therapy and photodiagnosis. Photochemical and Photobiological Sciences, 17, 1553-1572. 